\title{
CDK6 is stimulated by hyperthermia and protects gastric cancer cells from hyperthermia-induced damage
}

\author{
GUANGHUI LIU, HONGCHAO ZHAO, QINGQING DING, HAOHAO LI, \\ TAO LIU, HONGWEI YANG and YUANHUA LIU
}

\begin{abstract}
Department of Gastrointestinal Surgery, The First Affiliated Hospital of Zhengzhou University, Zhengzhou, Henan 450008, P.R. China
\end{abstract}

Received June 20, 2020; Accepted December 15, 2020

DOI: $10.3892 / \mathrm{mmr} .2021 .11879$

\begin{abstract}
Hyperthermia is one of the most widely employed adjuvant treatments for cancer, especially for hyperthermic intraperitoneal chemotherapy, and has few side effects. Gastric cancer has various hyperthermia sensitivities, but the exact molecular mechanisms remain to be elucidated. In the present study, western blotting was performed to detect differential expression of proteins that have been reported to be upregulated in gastric cancer. Following knockdown of these proteins, apoptosis was measured by Annexin V-FITC/propidium iodide (PI) double staining and hyperthermia treatment was applied. To evaluate the effect of cyclin-dependent kinase 6 (CDK6) on hyperthermia-induced apoptosis, CDK6 was knocked down or inhibited by the addition of a specific inhibitor and subsequent PI staining and cell proliferation, migration and invasion assays were performed. Hyperthermia-induced protein kinase B (AKT) expression and phosphorylation inhibition were detected. As demonstrated in the present study, the hyperthermia-induced proteins kinesin family member 11 (KIF11), cyclin-dependent kinase 6 (CDK6), stromal antigen 2, NIMA-related kinase 2 and karyopherin subunit $\alpha 4$ were highly expressed in gastric cancer cells, including SH-10-TC and HGC-27 cells. Knockdown of KIF11 significantly increased apoptosis without hyperthermia treatment and CDK6 significantly increased hyperthermia-induced apoptosis, prompting the present study to focus on CDK6. It was further confirmed that CDK6 activity was critical for decreasing hyperthermia-induced apoptosis and for cell proliferation. Hyperthermia-induced AKT expression and phosphorylation inhibition is potentially the main cause of CDK6 transcriptional upregulation. Taken together, these
\end{abstract}

Correspondence to: Professor Guanghui Liu, Department of Gastrointestinal Surgery, The First Affiliated Hospital of Zhengzhou University, 1 Jianshe East Road, Zhengzhou, Henan 450008, P.R. China

E-mail: guanghui1015@126.com

Key words: hyperthermia, apoptosis, cyclin-dependent kinase 6, protein kinase $\mathrm{B}$, gastric cancer findings demonstrated that CDK6 is upregulated via hyperthermia-induced AKT inhibition and subsequently protected gastric cancer cells from hyperthermia-induced apoptosis, indicating that it is a potential therapeutic target to sensitize gastric cancer cells to hyperthermia-based therapy.

\section{Introduction}

Gastric cancer is one of the commonest types of cancers worldwide (1), with widespread geographic variation in its prevalence in East Asia, South and Central America and Eastern Europe (2). Gastric cancer has a poor prognosis because of the likelihood of recurrence following curative surgery; recurrence occurs in $\sim 30-50 \%$ of patients despite the use of different surgical strategies, including D2 lymphadenectomy and D2 gastrectomy $(3,4)$. Peritoneal recurrence occurs in $\sim 10-45 \%$ of patients following curative surgery $(3,5)$. Multiple strategies have been developed for peritoneal recurrence, including adjuvant chemotherapy $(4,6)$, neoadjuvant chemotherapy (7) and adjuvant chemoradiation (8); however, none of them successfully lower the rate of distant metastasis.

Hyperthermic intraperitoneal chemotherapy (HIPEC) is an adjunctive strategy to surgery. It is performed by employing a heated solution containing cytotoxic drugs and intended to destroy tumor cells that remain following tumor removal or existing tumor cells in the peritoneum (which can later lead to recurrence) (9). Hyperthermia is critical for HIPEC, in which the malignant tumor is exposed to temperatures $\geq 40-43^{\circ} \mathrm{C}$, which induce apoptosis of tumor cells mainly by disrupting cytoskeleton components, changing membrane permeability and inhibiting tumor cell growth (10). However, the exact mechanism of the positive therapeutic effects of hyperthermia remains to be elucidated.

It has been known for over three decades that cancer cells present markedly more sensitivity to mild hyperthermia than normal or nontumor cells $(11,12)$. Several mechanisms have been proposed for how hyperthermia kills tumor cells, including disruption of plasma membrane protein and cytoskeletal distribution, induction of reactive oxygen species, disturbance of mitochondrial membrane potential, promotion of cell apoptosis and arrest of cell cycle phases $(13,14)$. All these hyperthermic effects may be due to a change in global gene expression in tumor cells. Studies have evaluated heat 
shock-induced changes in global gene expression in tumor cells and identify several genes involved in the regulation of apoptosis, the cell cycle and cell structure/maintenance $(15,16)$, including kinesin family member 11 (KIF11), cyclin-dependent kinase 6 (CDK6), PAGE family member 2 (PAGE2), NIMA-related kinase 2 (NEK2) and karyopherin subunit $\alpha 4$ (KPNA4). These findings have raised further questions regarding the roles of these genes in gastric cancer cells and in hyperthermia-induced cell damage.

The cell cycle kinase CDK6 has been recognized not only as a typical cyclin-dependent kinase but also as a transcriptional regulator of a number of genes and its effects may be dependent on or independent of its kinase activity $(15,16)$. CDK6 tightly regulates the $G_{1}$ to $S$ cell cycle transition and negatively regulates cell differentiation (17). In gastric cancer cells, CDK6 has been reported to interact with EGFR and promote malignant behaviors, including cell proliferation, migration and invasion, while increasing chemoresistance (18). As CDK6 is also upregulated by hyperthermia treatment, it was hypothesized that CDK6 may be induced by hyperthermia and regulate tumor progression.

The purpose of the present study was to investigate whether effects on CDK6 induced by hyperthermia are involved in regulating malignant behaviors and hyperthermia-induced cell injury. By identifying the potential roles of CDK6 in hyperthermia-induced cell injury, the results suggested CDK6 as a promising therapeutic target for enhancing sensitivity to hyperthermia in gastric cancer.

\section{Materials and methods}

Cell culture. The Human gastric cancer cell lines SH-10-TC, HGC-27 and epithelial cell line GES-1 were bought from the American Type Culture Collection and frozen in liquid nitrogen $\left(\sim-196^{\circ} \mathrm{C}\right)$ in the Department of Gastrointestinal Surgery, the First Affiliated Hospital of Zhengzhou University (Zhengzhou, China). They were cultured in DMEM (Thermo Fisher Scientific, Inc.) supplemented with 10\% FBS, $100 \mathrm{U} / \mathrm{ml}$ penicillin and $100 \mu \mathrm{g} / \mathrm{ml}$ streptomycin (Thermo Fisher Scientific, Inc.). Cells were maintained at $37^{\circ} \mathrm{C}$ in $5 \% \mathrm{CO}_{2}$ and passaged every 3-4 days.

Gene expression profiling interactive analysis (GEPIA). The relative expression levels in gastric cancer samples of KIF11, CDK6, stromal antigen 2 (STAG2), NEK2 and KPNA4 compared with adjacent non-tumor samples were analyzed in GEPIA (gepia.cancer-pku.cn; release date, 2017). The mRNA levels of these genes in 407 gastric cancer samples and 211 adjacent non-tumor samples were obtained from The Cancer Genome Atlas (TCGA) database. Statistical analyses were performed using an unpaired Student's t-test for two independent groups and the cut-off was $\mathrm{P}<0.01$.

Western blot analysis. Rabbit monoclonal anti-human KIF11 antibody (cat. no. ab254298), rabbit anti-human CDK6 antibody (cat. no. ab124821), goat polyclonal anti-human STAG2 antibody (cat. no. ab4463), rabbit anti-human NEK2 antibody (cat. no. ab227958), goat anti-human KPNA4 antibody (cat. no. ab6039), rabbit anti-pan-AKT antibody (cat. no. ab8805), rabbit anti-AKT (Ser473) antibody (cat. no. ab81283), rabbit anti-AKT (Thr308) antibody (cat. no. ab38449) and mouse monoclonal anti- $\beta$-actin antibody (cat. no. ab8226) were bought from Abcam, diluted at 1:1,000 and used following the manufacturer's instructions.

Cells were lyzed using a SoniConvert ${ }^{\circledR}$ sonicator (DocSense) to obtain cell lysate following the manufacturer's instruction. Total protein was quantitatively measured using a BCA kit (Sigma-Aldrich; Merck KGaA). Total protein $(30 \mu \mathrm{g})$ was fractionated using 6-12\% gradient Tris-glycine gels and transferred onto PVDF membranes. The PVDF membranes were blocked in 5\% milk/Tris-buffered saline (TBS) buffer at room temperature for $30 \mathrm{~min}$ followed by an incubation with primary antibodies at $4^{\circ} \mathrm{C}$ overnight. After washing with PBS-T (containing 0.1\% Tween-20) three times, PVDF membranes were incubated with HRP-conjugated secondary antibodies for another $1 \mathrm{~h}$. The following secondary antibodies were used (all 1:5,000; Abcam): Goat anti-mouse IgG (HRP) secondary antibody (cat. no. ab97040); goat anti-rat IgG (HRP) secondary antibody (cat. no. ab7097); and donkey anti-goat IgG (HRP) secondary antibody (cat. no. ab7125). Blots were developed using the Pierce ECL Western Blotting Substrate (Thermo Fisher Scientific, Inc.) according to the manufacturer's instructions. Protein expression was semi-quantified via densitometry using ImageJ software (version-2.0; National Institutes of Health) with $\beta$-actin as the loading control.

Short interfering (si)RNA transfection. Knockdown of mRNA level of KIF11, CDK6, PAG2, NEK2 and KPNA4 were achieved by transient transfection of cells with (si)RNA duplexes. siRNA duplexes of KIF11 (cat. no. 4390844), CDK6 (cat. no. 4390824), PAG2 (cat. no. 289806), NEK2 (cat. no. 143612) and KPNA4 (cat. no. 143404) were purchased from Thermo Fisher Scientific, Inc. The commercial specific siRNAs were provided by Thermo Fisher Scientific, Inc.; negative control (siNC) sense 5'-GUUCAAUAUUAUCAA GCGGUU-3' and antisense 5'-CCGCUUGAUAAUAUUGAA CUU-3' was employed as negative control without specific target. siRNA transfection was performed by following manufacturer's protocol. Briefly, 5x10 5 cells were grown in $2 \mathrm{ml}$ of serum-free medium. A siRNA/transfection reagent complex was formed at room temperature by combining siRNA oligomer $(50 \mathrm{nM})$ with $5 \mu \mathrm{l}(2 \mu \mathrm{g} / \mathrm{ml})$ Lipofectamine ${ }^{\circledR} 2000$ transfection reagent (Thermo Fisher Scientific, Inc.) in $0.5 \mathrm{ml}$ OptiMEM medium (Thermo Fisher Scientific, Inc.) and this was applied to the cells for $48 \mathrm{~h}$ until they were harvested. Cells transfected with NC siRNA were considered as control cells. Successful knockdown of target gene was confirmed by performing quantitative PCR (qPCR).

Apoptosis assay. The apoptosis of cells was analyzed performing Annexin V-FITC/propidium iodide (PI)-double staining followed by fluorescence-activated cell sorting analysis using Annexin V Apoptosis Detection kit FITC (cat. no. 88-8005-72; eBioscience; Thermo Fisher Scientific, Inc.). Briefly, $5 \times 10^{4}$ cells were grown in a 6 -well plate. Following $37^{\circ} \mathrm{C}$ or $42^{\circ} \mathrm{C}$ pre-incubation for $2 \mathrm{~h}$ and another $24-\mathrm{h}$ incubation under $37^{\circ} \mathrm{C}$, cells were trypsinized, washed with PBS, resuspended in $200 \mu \mathrm{l}$ PBS with $10 \mu \mathrm{l}$ RNAase $(10 \mathrm{mg} / \mathrm{ml})$ and incubated at $37^{\circ} \mathrm{C}$ for $30 \mathrm{~min}$. At the end of incubation, $50 \mu \mathrm{l}$ Annexin V-FITC/PI labeling solution (BD Biosciences) 
was added and cells were analyzed for apoptosis using a flow cytometer (BD FACS Canto II; BD Biosciences). The results were analyzed using FlowJo software (version 9.7.4; Tree Star, Inc.). Apoptotic cells were defined as Annexin V-FITC ${ }^{+}$cells.

Cell cycle analysis. To analyze cell cycle phases by quantification of DNA content, cells harvested by trypsin were washed with ice-cold PBS for three times to remove the medium. The cells were fixed with ice-cold $70 \%$ ethanol overnight at $4^{\circ} \mathrm{C}$. Fixed cells were pelleted under $1,000 \mathrm{x}$ g centrifugation and the supernatant was removed followed by three washes with ice-cold PBS. Cells were incubated with final concentration of $100 \mu \mathrm{g} / \mathrm{ml}$ RNase A and $40 \mu \mathrm{g} / \mathrm{ml}$ PI (Beyotime Institute of Biotechnology) for $15 \mathrm{~min}$ in dark. The cells were analyzed by a 3 laser Navios flow cytometer (Beckman Coulter, Inc.) and the results were analyzed using ModFit analysis software program (version 4.0; Verity Software House, Inc.).

Reverse transcription- $q P C R(R T-q P C R)$. To isolate total RNA from cells, TRIzol ${ }^{\circledR}$ (Thermo Fisher Scientific, Inc.) was used according to the manufacturer's instructions. Subsequently, total RNA $(1 \mu \mathrm{g})$ was reverse transcribed into cDNA using a High-Capacity cDNA Reverse Transcription kit (cat. no. 4368814, Thermo Fisher Scientific, Inc.) according to the manufacturer's instruction. qPCR was performed using PowerUp SYBR Green Master Mix (cat. no. A25918; Thermo Fisher Scientific, Inc.) and an ABI 7500 system (Applied Biosystems; Thermo Fisher Scientific, Inc.) and the following thermocycling conditions: $95^{\circ} \mathrm{C}$ for $10 \mathrm{~min}$, 40 cycles of $95^{\circ} \mathrm{C}$ for $30 \mathrm{sec}, 55^{\circ} \mathrm{C}$ for $30 \mathrm{sec}$ and $72^{\circ} \mathrm{C}$ for $1 \mathrm{~min}$. The following primers were used for qPCR: CDK6 forward, 5'-GCTGACCAGCAGTACGAATG-3' and reverse, 5'-GCACACATCAAACAACCTGACC-3'; AKT forward, 5'-AGCGACGTGGCTATTGTGAAG-3' and reverse, 5'-GCC ATCATTCTTGAGGAGGAAGT-3'; $\beta$-actin forward, 5'-CAT GTACGTTGCTATCCAGGC-3' and reverse, 5'-CTCCTT AATGTCACGCACGAT-3'. mRNA expression levels were quantified using the $2^{-\Delta \Delta \mathrm{Cq}}$ method (19) and normalized to the internal reference gene $\beta$-actin.

High-content screening (HCS)-based functional assay. The numbers of cells of HGC-27 following CDK6 knockdown or inhibition were observed for 4 days using an ImageXpress ${ }^{\circledR}$ Micro XLS High-Content Screening (HCS) system (Molecular Devices, LLC), according to the manufacturer's protocols. Briefly, at $24 \mathrm{~h}$ post-transfection, cells were plated in 96-well plates and imaged every $24 \mathrm{~h}$. Then the images were analyzed using MetaXpress software (version 3.1; Molecular Devices, LLC).

Migration and invasion. Transwell permeable plates with $8 \mu \mathrm{m}$ pores (Corning Life Sciences) was used for analyzing cell migration and invasion. For measuring migration ability, cells $\left(5 \times 10^{3}\right)$ were suspended and plated into upper chamber (8 $\mu \mathrm{m}$ pore size; Corning Life Sciences). For measuring invasion ability, cells $\left(5 \times 10^{3}\right)$ suspended in serum-free DMEM were plated into the upper chamber ( $8 \mu \mathrm{m}$ pore size; Corning Life Sciences), which was precoated with Matrigel at room temperature for $4 \mathrm{~h}$ (Sigma-Aldrich; Merck KGaA). The low chamber contained $500 \mu \mathrm{l}$ of serum-free DMEM medium supplemented with $1 \%$ FBS. To the upper chamber, $1 \times 10^{4}$ cells were added suspended in serum-free medium. After $24 \mathrm{~h}$ the cells in the chamber were fixed with $4 \%$ paraformaldehyde at room temperature for $10 \mathrm{~min}$ and stained with $0.25 \%$ crystal violet (Sigma-Aldrich; Merck KGaA) at room temperature for $30 \mathrm{~min}$. Migratory and invading cells were visualized using an X71 (U-RFL-T) fluorescence microscope (Olympus Corporation; magnification, $\mathrm{x} 40$ ).

Statistical analysis. All experiments in the present study were repeat three times independently. An unpaired Student's t-test or one-way ANOVA followed by Tukey's post hoc test was used to compare two or multiple groups, respectively. All data in this study was presented as the mean \pm standard deviation. $\mathrm{P}<0.05$ was considered to indicate a statistically significant difference.

\section{Results}

Association between potential hyperthermic-responding proteins and gastric cancer. As tumor cells demonstrate significantly more sensitivity to hyperthermia $(11,12)$, the present study aimed to investigate the potential association between hyperthermic responding proteins and gastric cancer. According to a previous study (20), mRNA levels of KIF11, CDK6, STAG2, NEK2 and KPNA4 are stimulated by hyperthermic incubation in cancer cells. Thus, the present study investigated their expression levels in gastric cancer samples by employing GEPIA to analyze RNA sequencing data in TCGA. In GEPIA, the expression levels of these five genes was analyzed in cancer samples $(n=407)$ compared with adjacent non-tumor samples $(n=211)$. In general, the five genes presented higher expression levels in cancer samples compared with adjacent non-tumor samples (Fig. 1A). To confirm whether the high expression of these genes existed in gastric cancer cell lines, gastric cancer cell lines SH-10-TC, HGC-27 were used. Compared with human gastric epithelial cells GES-1, protein levels of KIF11, CDK6, STAG2, NEK2 and KPNA4 were significantly higher in gastric cancer cell lines (Fig. 1B and C). These data indicated that KIF11, CDK6, STAG2, NEK2 and KPNA4 were potentially involved in gastric cancer progression and involved in regulating hyperthermic response.

CDK6 may protect gastric cancer cells from hyperthermicinduced apoptotic cell death. To further investigate the role of hyperthermic responding protein in hyperthermia treatment, instead of overexpression due to high endogenous level, KIF11, CDK6, STAG2, NEK2 and KPNA4 were knocked down by transfecting specific siRNAs (Fig. 2A). Cells were pretreated at $37^{\circ} \mathrm{C}$ or $42^{\circ} \mathrm{C}$ for $2 \mathrm{~h}$ and incubated under $37^{\circ} \mathrm{C}$ for another $24 \mathrm{~h}$, followed by apoptotic analysis using Annexin V-FITC/PI double staining. As shown in Fig. 2B and C, 2-h pretreatment of hyperthermia induced cell apoptosis and knockdown of both KIF11 and CDK6 significantly increased apoptotic induction of hyperthermia. Knockdown of the other three proteins, STAG2, NEK2 and KPNA4, failed to notably affect apoptosis induced by hyperthermic pretreatment, indicating that KIF11 and CDK6 may be critical for regulating hyperthermic-induced cell death. 

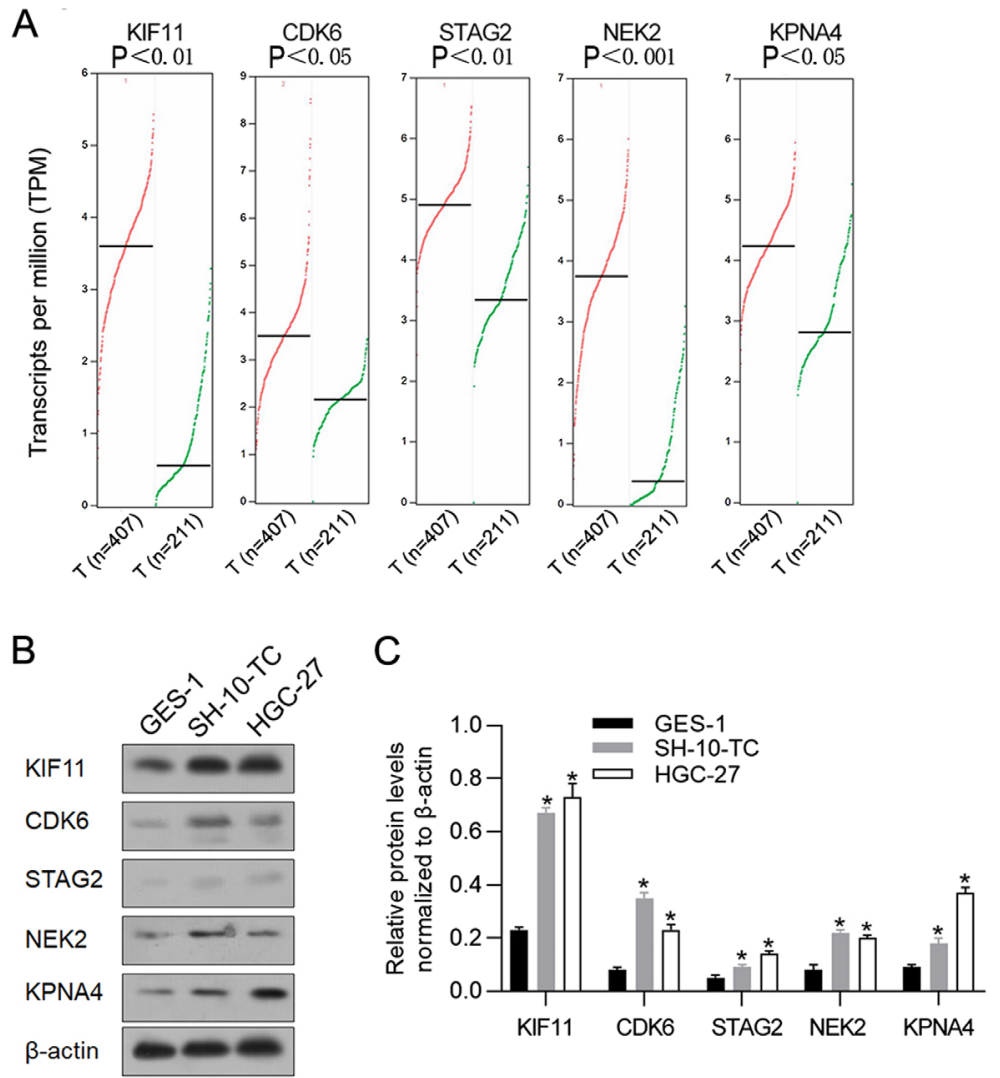

Figure 1. Expression levels of KIF11, CDK6, STAG2, NEK2 and KPNA4 in gastric cancer samples and cell lines. (A) the GEPIA database revealed that KIF11, CDK6, STAG2, NEK2 and KPNA4 expression levels were significantly upregulated in gastric cancer tissues $(\mathrm{n}=407)$ compared with adjacent tissues $(\mathrm{n}=211)$. (B) Western blot analysis was performed to detect relative protein levels of KIF11, CDK6, STAG2, NEK2 and KPNA4 in gastric cancer cell lines SH-10-TC and HGC-27, compared with gastric epithelial cell line GES-1. (C) Relative protein levels of KIF11, CDK6, STAG2, NEK2 and KPNA4 in gastric cancer cell lines SH-10-TC and HGC-27 were normalized to $\beta$-actin. "P<0.05, vs. GES-1 group. KIF11, kinesin family member 11; CDK6, cyclin-dependent kinase 6; STAG2, stromal antigen 2; NEK2, NIMA-related kinase 2; KPNA4, karyopherin subunit $\alpha$ 4; GEPIA Gene Expression Profiling Interactive Analysis.

A
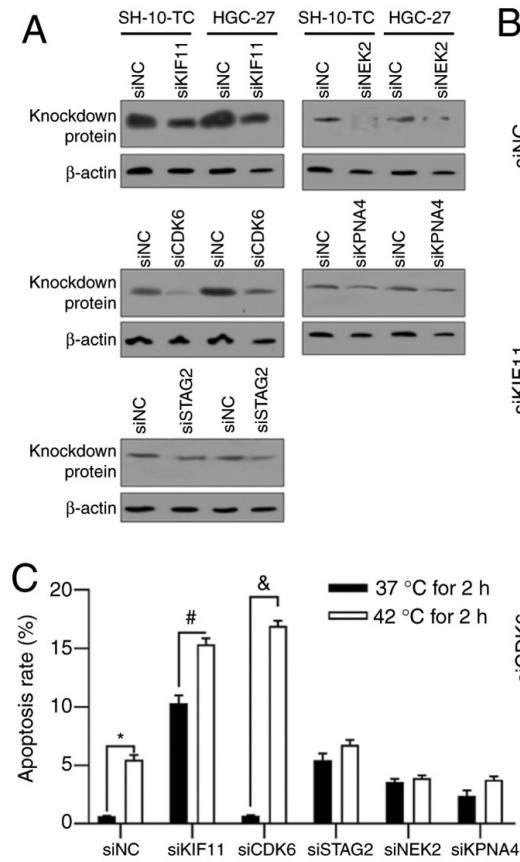

B
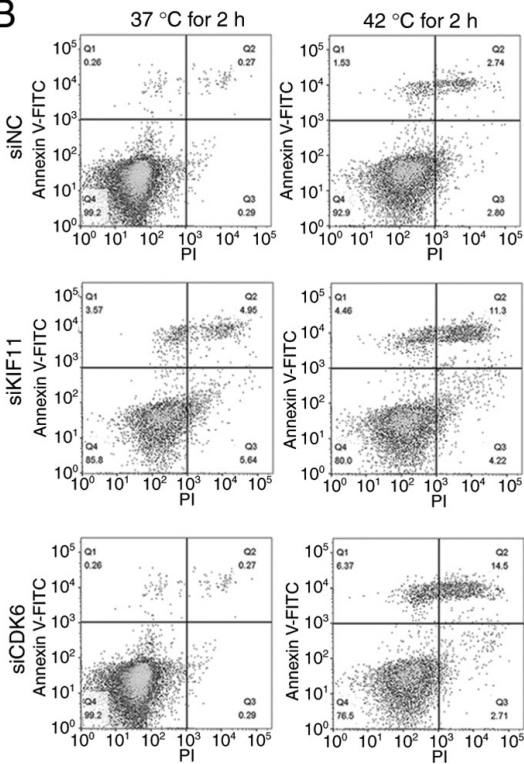
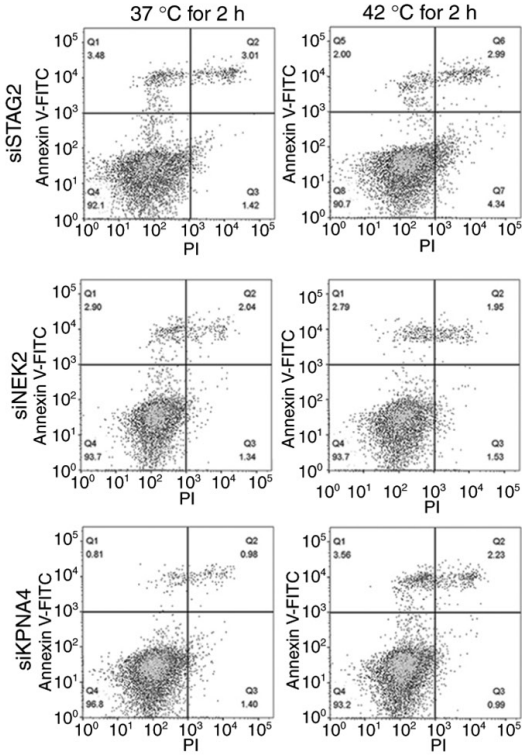

Figure 2. Regulation of KIF11, CDK6, STAG2,NEK2 and KPNA4 on hyperthermic-induced apoptosis in HGC-27 cells. (A) At $48 \mathrm{~h}$ following siRNA transfection, protein levels of KIF11, CDK6, STAG2, NEK2 and KPNA4 were analyzed by western blotting to confirm the knockdown efficacy. (B and C) Following $2 \mathrm{~h}$ pre-incubation at $37^{\circ} \mathrm{C}$ or $42^{\circ} \mathrm{C}$, cell apoptosis was analyzed by performing Annexin V-FITC/PI double staining followed by follow cytometric analysis ${ }^{*} \mathrm{P}<0.05$ vs. siNC $/ 37^{\circ} \mathrm{C} 2 \mathrm{~h}$-pre-incubated group; ${ }^{*} \mathrm{P}<0.05$ vs. siKIF $11 / 37^{\circ} \mathrm{C} 2 \mathrm{~h}$-pre-incubated group; ${ }^{\circledR} \mathrm{P}<0.05$ vs. siCDK6/37 ${ }^{\circ} \mathrm{C} 2 \mathrm{~h}$-pre-incubated group. KIF 11 , kinesin family member 11; CDK6, cyclin-dependent kinase 6; STAG2, stromal antigen 2; NEK2, NIMA-related kinase 2; KPNA4, karyopherin subunit $\alpha$ 4; PI, propidium iodide; si, short interfering; NC, negative control. 

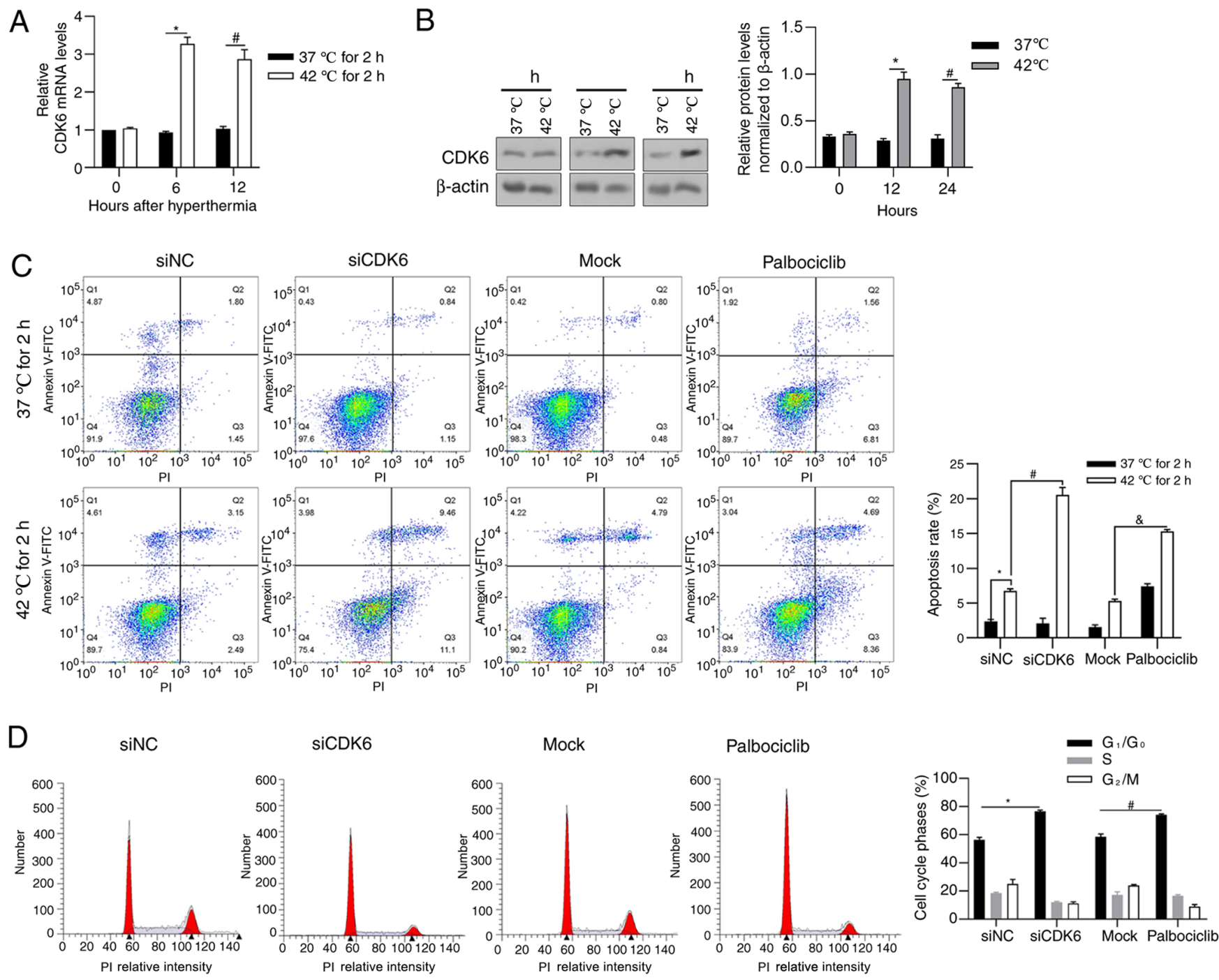

Figure 3. CDK6 is transcriptionally induced by hyperthermia and exerts pro-survival effect on HGC-27 cells. (A) Reverse transcription-quantitative PCR was performed to detect CDK6 mRNA levels following $0,6,12 \mathrm{~h}$ of hyperthermia treatment. ${ }^{*} \mathrm{P}<0.05$ vs. $37^{\circ} \mathrm{C}$ for $2 / 6 \mathrm{~h}$ extra incubation; ${ }^{*} \mathrm{P}<0.05$, vs. $37^{\circ} \mathrm{C}$ for $2 / 12 \mathrm{~h}$ extra incubation. (B) Western blotting was performed to detect CDK6 protein following 0,12 and $24 \mathrm{~h}$ of hyperthermia treatment. ${ }^{*} \mathrm{P}<0.05$ vs. $37^{\circ} \mathrm{C}$ for $12 \mathrm{~h}$ group ${ }^{\sharp} \mathrm{P}<0.05$, vs. $37^{\circ} \mathrm{C}$ for $24 \mathrm{~h}$ group. (C) Following CDK6 knockdown or inhibition by adding Palbociclib, the apoptosis rate was measured by performing Annexin-FICT/PI double staining. " $\mathrm{P}<0.05$ vs. siNC $/ 37^{\circ} \mathrm{C}$ for $2 \mathrm{~h}$ group; ${ }^{\prime} \mathrm{P}<0.05$, vs. siNC $/ 42^{\circ} \mathrm{C}$ for $2 \mathrm{~h}$ group; ${ }^{\circledR} \mathrm{P}<0.05$ vs. mock $/ 42^{\circ} \mathrm{C}$ for $2 \mathrm{~h}$ group. (D) The effect of CDK6 knockdown or inhibition on cell cycle distribution without hyperthermia treatment was measured by performing PI staining followed by flow cytometry analysis. " $\mathrm{P}<0.05$ vs. siNC group; " $\mathrm{P}<0.05$ vs. mock group. CDK6, cyclin-dependent kinase 6; PI, propidium iodide; si, short interfering; NC, negative control.

Markedly, knockdown of KIF11 promoted apoptotic cell death under $37^{\circ} \mathrm{C}$, indicating that its effect on apoptosis may not be related to hyperthermia treatment and thus the present study focused on CDK6.

CDK6 is induced by hyperthermia treatment and exerts a pro-survival effect with hyperthermia. To examine the expression level of CDK6 in HCG-27 cells under hyperthermia, RT-qPCR was performed to detect CDK6 mRNA after 0,6 and $12 \mathrm{~h}$ and western blot analysis was performed to detect CKD6 protein after 0,12 and $24 \mathrm{~h}$. As shown in Fig. 3A and B, hyperthermia significantly increased CDK6 transcriptionally at 6 and $12 \mathrm{~h}$ time points following 2-h hyperthermia treatment and an increasing trend in protein level was also observed after 12 and $24 \mathrm{~h}$. Palbociclib, a CDK6 inhibitor against its phosphorylating activity, was employed to access the effect of CDK6 on the regulation of cell behavior under hyperthermia. As shown in Fig. 3C, CDK6 knockdown and inhibition increased apoptotic cell death under hyperthermia, demonstrating that CDK6 protects cells from hyperthermic-induced apoptosis, at least partly, depending on its phosphorylation activity. To investigate its critical effect on cell cycle processes, cell cycle distribution was analyzed following CDK6 knockdown or inhibition. CDK6 knockdown and inhibition both blocked cell cycle at $\mathrm{G}_{1} / \mathrm{G}_{0}$ (Fig. 3D).

To further examine the effect of CDK6 on proliferation, HSC-based cell viability assay was performed. As shown in Fig. 4A and B, the presence of CDK6 and activity of CDK6 are critical for maintaining proliferation in HGC-27 cells. Whether CDK6 affected other malignant behaviors, including migration and invasion was also assessed. When incubated in serum-free medium, CDK6 failed to affect cell proliferation (Fig. 4C), indicating that CDK6 mainly regulated HGC-27 via its regulatory role in proliferation. 


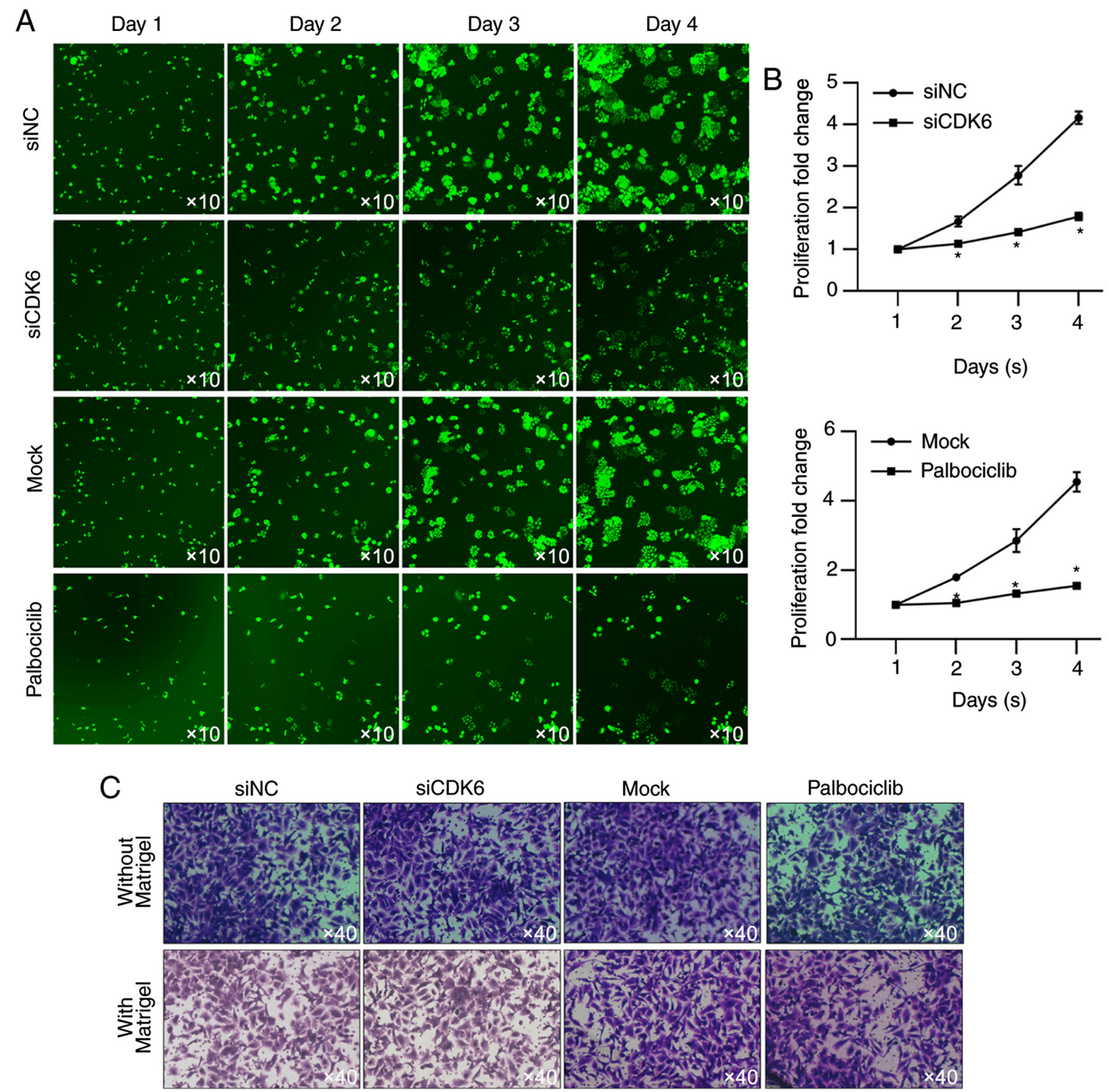

Figure 4. CDK6 promotes cell proliferation without disturbing other malignant behaviors, including migration and invasion. (A) Cell proliferation was observed to identify cell morphology from day 1 to day 4 following CDK6 knockdown and inhibition. (B) Relative proliferation rate was normalized to that of day $1 .{ }^{*} \mathrm{P}<0.05$ vs. siNC group (upper panel); ${ }^{*} \mathrm{P}<0.05$ vs. siNC group (lower panel). (C) Transwell assay without Matrigel (upper panel) and with Matrigel (lower panel) was performed. CDK6, cyclin-dependent kinase 6; si, short interfering; NC, negative control.

Hyperthermia suppresses expression and phosphorylation of protein kinase $B(A K T)$ and can increase CDK6 transcriptionally. To investigate how CDK6 was regulated by hyperthermia in cancer cells, the potential role of serine/threonine kinase AKT, which is reported to transcriptionally inhibit CDK6 in breast cancer cells (21) and be inhibited by hyperthermia (22) was examined. An AKT inhibitor, MK2206, which inhibits phosphorylation of AKT at Ser473 and Thr308, was used to assess the regulation of AKT on CDK6. As shown in Fig. $5 \mathrm{~A}, 42^{\circ} \mathrm{C}$ treatment and addition of MK2206 significantly decreased AKT protein level. AKT phosphorylation at Ser473 and Thr308 increased CDK6 protein level (Fig. 5A), which indicated that AKT activity inhibited by hyperthermia may be a critical regulator of CDK6. To assess whether AKT transcriptionally regulated CDK6, RT-qPCR was performed following hyperthermia treatment or the addition of MK2206 and it was found that the expression level of AKT was negatively associated with CDK6, confirming its transcriptional regulation on CDK6 (Fig. 5B).

\section{Discussion}

The present study identified that CDK6 was highly expressed in gastric cancer cells compared with gastric epithelial cells and is further overexpressed in response to hyperthermia. Notably, CDK6 was upregulated in gastric cancer patient tissues and in gastric cancer cell lines. When CDK6 expression was downregulated, increased cell apoptosis induced by hyperthermia treatment and an inhibitory effect on cell proliferation via blockade of the cell cycle at the $\mathrm{G}_{1}$ phase was observed, but there were no effects on migration or invasion. It was further observed that hyperthermia treatment inhibited AKT expression and phosphorylation, which may be critical for the upregulation of CDK6.

In global gene expression affected by heat shock-induced change, KIF11, CDK6, PAGE2, NEK2 and KPNA4 are reported to be markedly changed in the regulation of apoptosis, the cell cycle and cell structure and/or maintenance $(15,16)$. Their relative expression, as measured from TCGA database, 
A
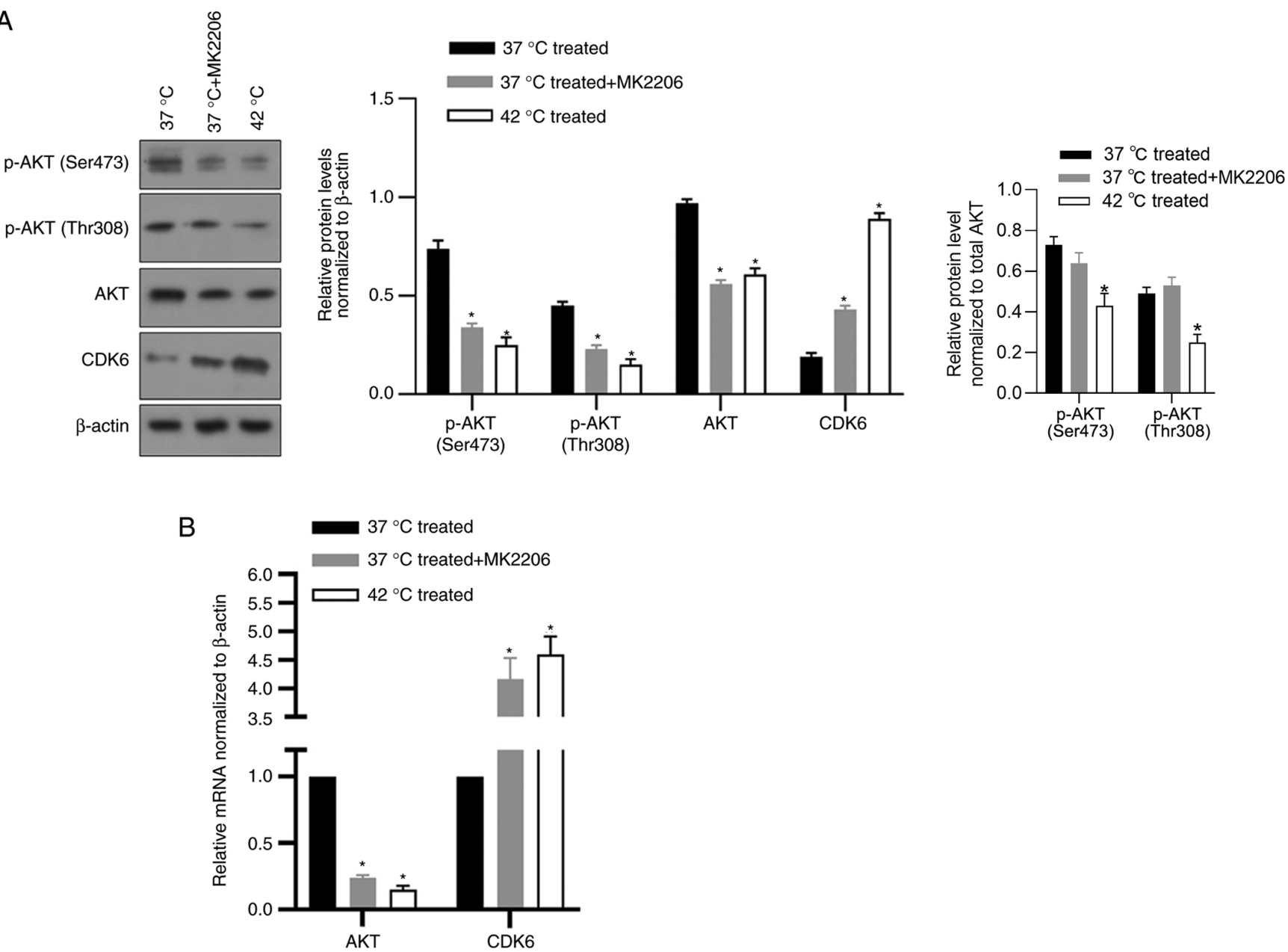

Figure 5. CDK6 is potentially stimulated by AKT inhibition induced by hyperthermia treatment. (A) Following hyperthermia treatment or addition of AKT inhibitor, MK2206, protein levels of CDK6, AKT and phosphorylation forms of AKT (Ser473 and Thr308) were detected by western blot. "P $<0.05$ vs. $37^{\circ} \mathrm{C}$ group. (B) Reverse transcription-quantitative PCR was performed to detect mRNA levels of AKT and CDK6 following hyperthermia treatment or addition of AKT inhibitor, MK2206. " $\mathrm{P}<0.05$ vs. $37^{\circ} \mathrm{C}$ group. CDK6, cyclin-dependent kinase 6; AKT, protein kinase B; p-, phosphorylated.

showed no association between clinicopathological features ,due to the lack of online data. In further investigation, it is hoped to perform these analyses.

The cell cycle kinase CDK6 has been recognized as not only functioning as a typical cyclin-dependent kinase but also acting as a transcriptional regulator with distinct properties from its close homologue CDK4 $(23,24)$. As a transcriptional regulator, CDK6 controls the transcription of numerous genes in both a kinase activity-dependent and -independent manner (25) and regulates malignant behaviors in several types of cancers $(21,26,27)$. Scheicher et al (28) reported that in leukemic stem cells, CDK6 transcriptionally regulates Egr1, a critical factor for hematopoietic stem cell and leukemic stem cell activation and thus results in leukemia tumorigenesis. It has also been reported that CDK6 physically interacts with forkhead box $\mathrm{O} 3$ (FOXO3) and thus stabilizes it to cause resistance of epithelial ovarian cancer cells to platinum-induced cell death (27). CDK6 is also found to exert critical regulatory roles in tumorigenesis by acting as a kinase and antagonizing the p53-induced antitumor response (26). Taken together, these findings show that CDK6 is intricately involved in tumor regulation, indicating its potential role in regulating hyperthermia-induced cell damage.
In addition to determining the effect of CDK6 on malignant behaviors, the effect of CDK6 on hyperthermia-induced cell apoptosis was investigated. The presence of CDK6 inhibited hyperthermia-induced cell apoptosis and hyperthermia treatment significantly upregulated CDK6 protein levels. These findings indicated that upregulation of CDK6 in gastric cancer tissues compared with adjacent tissues could predict poor prognosis due to potential insensitivity to hyperthermia and chemotherapy, supporting the idea that CDK6 could represent a viable therapeutic target.

In breast cancer cells, the CDK6 promoter is transcriptionally regulated by the FOXO3/bromodomain-containing protein 4 complex, which is phosphorylated and activated by AKT (21). The addition of the AKT inhibitor MK2206 transcriptionally stimulated CDK6 expression. In the present study, the addition of MK2206 and siRNA-mediated AKT knockdown in HGC-27 cells significantly increased CDK6 mRNA and protein levels, which is consistent with previous findings (21). Narikawa et al (22) reported that hyperthermia treatment suppresses AKT signaling by decreasing its protein level and phosphorylation. The hypothesis of the present study was that hyperthermia may upregulate CDK6 by causing AKT suppression. HGC27 is an unique gastric cancer cell 
line derived from lymph node metastasis, therefore the results should be validated by further investigation in other cell lines.

In conclusion, the associations between the expression of several genes and sensitivity to hyperthermia in gastric cancer cells has been detailed. The analyses of the present study revealed that CDK6 had a role in promoting cell proliferation and in preventing hyperthermia-induced cell apoptosis in gastric cancer cells. It is hypothesized that CDK6 was upregulated in gastric cancer cells and promoted both malignancy and resistance to hyperthermia, which are known to promote the development and progression of cancer as well as failure of therapy. The present findings support the hypothesis that CDK6 is a potential therapeutic target in the treatment of gastric cancer.

\section{Acknowledgements}

The authors would like to thanks for Mr. Tao Hong (Sichuan University) for language editing and the suggestions for statistical analysis.

\section{Funding}

No funding was received.

\section{Availability of data and materials}

The datasets generated and/or analyzed during the current study are available from the corresponding author on reasonable request.

\section{Authors' contributions}

GL, HZ and QD designed the experiments. GL, HL, TL, YL and HY performed the experiments. GL and QD were responsible for data collection and performed statistical analysis. All authors read and approved the final manuscript.

\section{Ethics approval and consent to participate}

Not applicable.

\section{Patient consent for publication}

Not applicable.

\section{Competing interests}

The authors declare that they have no competing interests.

\section{References}

1. Parkin DM, Bray F, Ferlay J and Pisani P: Global cancer statistics, 2002. CA Cancer J Clin 55: 74-108, 2005.

2. Torre LA, Siegel RL, Ward EM and Jemal A: Global cancer incidence and mortality rates and trends-an update. Cancer Epidemiol Biomarkers Prev 25: 16-27, 2016.

3. Thomassen I, van Gestel YR, van Ramshorst B, Luyer MD, Bosscha K, Nienhuijs SW, Lemmens VE and de Hingh IH: Peritoneal carcinomatosis of gastric origin: A population-based study on incidence, survival and risk factors. Int J Cancer 134 622-628, 2014
4. Sakuramoto S, Sasako M, Yamaguchi T, Kinoshita T, Fujii M, Nashimoto A, Furukawa H, Nakajima T, Ohashi Y, Imamura $\mathrm{H}$, et al: Adjuvant chemotherapy for gastric cancer with S-1, an oral fluoropyrimidine. N Engl J Med 357: 1810-1820, 2007.

5. D'Angelica M, Gonen M, Brennan MF, Turnbull AD, Bains M and Karpeh MS: Patterns of initial recurrence in completely resected gastric adenocarcinoma. Ann Surg 240: 808-816, 2004.

6. Bang YJ, Kim YW, Yang HK, Chung HC, Park YK, Lee KH, Lee KW, Kim YH, Noh SI, Cho JY, et al: Adjuvant capecitabine and oxaliplatin for gastric cancer after D2 gastrectomy (CLASSIC): A phase 3 open-label, randomised controlled trial. Lancet 379: 315-321, 2012.

7. Cunningham D, Allum WH, Stenning SP, Thompson JN, Van de Velde CJ, Nicolson M, Scarffe JH, Lofts FJ, Falk SJ, Iveson TJ, et al: Perioperative chemotherapy versus surgery alone for resectable gastroesophageal cancer. N Engl J Med 355: 11-20, 2006.

8. Smalley SR, Benedetti JK, Haller DG, Hundahl SA, Estes NC, Ajani JA, Gunderson LL, Goldman B, Martenson JA, Jessup JM, et al: Updated analysis of SWOG-directed intergroup study 0116: A phase III trial of adjuvant radiochemotherapy versus observation after curative gastric cancer resection. J Clin Oncol 30: 2327-2333, 2012.

9. Yurttas C, Hoffmann G, Tolios A, Haen SP, Schwab M, Königsrainer I, Königsrainer A, Beckert S and Löffler MW: Systematic review of variations in hyperthermic intraperitoneal chemotherapy (HIPEC) for peritoneal metastasis from colorectal cancer. J Clin Med 7: 567, 2018.

10. Tao Y, Guo Y, Liu W, Zhang J, Li X, Shen L, Ru Y, Xue Y, Zheng J, Liu X, et al: AKT inhibitor suppresses hyperthermia-induced Ndrg2 phosphorylation in gastric cancer cells. Braz J Med Biol Res 46: 394-404, 2013.

11. Habash RW, Bansal R, Krewski D and Alhafid HT: Thermal therapy, part 2: Hyperthermia techniques. Crit Rev Biomed Eng 34: 491-542, 2006.

12. Habash RW, Bansal R, Krewski D and Alhafid HT: Thermal therapy, part 1: An introduction to thermal therapy. Crit Rev Biomed Eng 34: 459-489, 2006.

13. Roti RJ: Cellular responses to hyperthermia (40-46 degrees C): Cell killing and molecular events. Int J Hyperthermia 24: 3-15, 2008.

14. Koutcher JA, Barnett D, Kornblith AB, Cowburn D, Brady TJ and Gerweck LE: Relationship of changes in $\mathrm{pH}$ and energy status to hypoxic cell fraction and hyperthermia sensitivity. Int J Radiat Oncol Biol Phys 18: 1429-1435, 1990.

15. Tabuchi Y, Wada S, Furusawa Y, Ohtsuka K and Kondo T: Gene networks related to the cell death elicited by hyperthermia in human oral squamous cell carcinoma HSC-3 cells. Int J Mol Med 29: 380-386, 2012.

16. Tabuchi Y, Takasaki I, Wada S, Zhao QL, Hori T, Nomura T, Ohtsuka $\mathrm{K}$ and Kondo T: Genes and genetic networks responsive to mild hyperthermia in human lymphoma U937 cells. Int J Hyperthermia 24: 613-622, 2008.

17. Malumbres M and Barbacid M: Mammalian cyclin-dependent kinases. Trends Biochem Sci 30: 630-641, 2005.

18. Jia Y, Zhao LM, Bai HY, Zhang C, Dai SL, Lv HL and Shan BE: The tumor-suppressive function of miR-1296-5p by targeting EGFR and CDK6 in gastric cancer. Biosci Rep 39: BSR20181556, 2019.

19. Livak KJ and Schmittgen TD: Analysis of relative gene expression data using real-time quantitative PCR and the 2(-Delta Delta C(T)) method. Methods 25: 402-408, 2001.

20. Amaya C, Kurisetty V, Stiles J, Nyakeriga AM, Arumugam A, Lakshmanaswamy R, Botez CE, Mitchell DC and Bryan BA: A genomics approach to identify susceptibilities of breast cancer cells to 'fever-range' hyperthermia. BMC Cancer 14: 81, 2014.

21. Liu J, Duan Z, Guo W, Zeng L, Wu Y, Chen Y, Tai F, Wang Y, Lin Y, Zhang Q, et al: Targeting the BRD4/FOXO3a/CDK6 axis sensitizes AKT inhibition in luminal breast cancer. Nat Commun 9: 5200, 2018

22. Narikawa M, Umemura M, Tanaka R, Fujita T, Yokoyama U, Ishigami T, Kimura K, Tamura K and Ishikawa Y: Acute hyperthermia inhibits TGF- $\beta 1$-induced cardiac fibroblast activation via suppression of Akt signaling. Sci Rep 8: 6277, 2018.

23. Kollmann K, Heller G, Schneckenleithner C, Warsch W, Scheicher R, Ott RG, Schäfer M, Fajmann S, Schlederer M, Schiefer AI, et al: A kinase-independent function of CDK6 links the cell cycle to tumor angiogenesis. Cancer Cell 24: 167-181, 2013. 
24. Hydbring P, Malumbres M and Sicinski P: Non-canonical functions of cell cycle cyclins and cyclin-dependent kinases. Nat Rev Mol Cell Biol 17: 280-292, 2016.

25. Tigan AS, Bellutti F, Kollmann K, Tebb G and Sexl V: CDK6-a review of the past and a glimpse into the future: From cell-cycle control to transcriptional regulation. Oncogene 35: 3083-3091, 2016.

26. Bellutti F, Tigan AS, Nebenfuehr S, Dolezal M, Zojer M, Grausenburger R, Hartenberger S, Kollmann S, Doma E, Prchal-Murphy $\mathrm{M}$, et al: CDK6 antagonizes p53-induced responses during tumorigenesis. Cancer Discov 8: 884-897, 2018

27. Dall'Acqua A, Sonego M, Pellizzari I, Pellarin I, Canzonieri V, D'Andrea S, Benevol S, Sorio R, Giorda G, Califano D, et al: CDK6 protects epithelial ovarian cancer from platinum-induced death via FOXO3 regulation. EMBO Mol Med 9: 1415-1433, 2017.
28. Scheicher R, Hoelbl-Kovacic A, Bellutti F, Tigan AS, Prchal-Murphy M, Heller G, Schneckenleithner C, Salazar-Roa M, Zöchbauer-Müller S, Zuber J, et al: CDK6 as a key regulator of hematopoietic and leukemic stem cell activation. Blood 125: 90-101, 2015.

(i) (3) This work is licensed under a Creative Commons Attribution-NonCommercial-NoDerivatives 4.0 International (CC BY-NC-ND 4.0) License. 